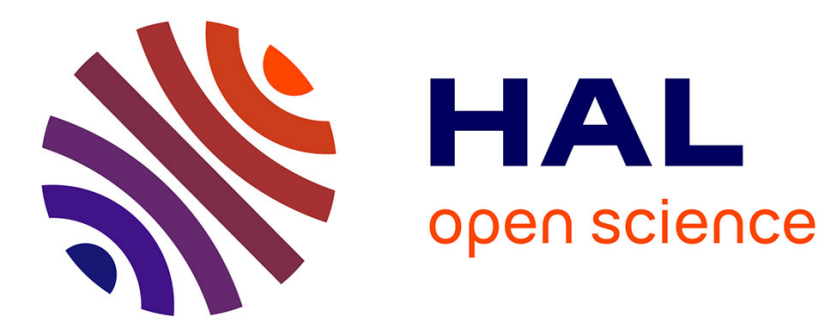

\title{
Global financial crisis, liquidity pressure in stock markets and efficiency of central bank interventions
}

Mohamed El Hedi Arouri, Fredj Jawadi, Duc Khuong Nguyen

\section{To cite this version:}

Mohamed El Hedi Arouri, Fredj Jawadi, Duc Khuong Nguyen. Global financial crisis, liquidity pressure in stock markets and efficiency of central bank interventions. 2010. hal-00507821

\section{HAL Id: hal-00507821 \\ https://hal.science/hal-00507821}

Preprint submitted on 1 Aug 2010

HAL is a multi-disciplinary open access archive for the deposit and dissemination of scientific research documents, whether they are published or not. The documents may come from teaching and research institutions in France or abroad, or from public or private research centers.
L'archive ouverte pluridisciplinaire HAL, est destinée au dépôt et à la diffusion de documents scientifiques de niveau recherche, publiés ou non, émanant des établissements d'enseignement et de recherche français ou étrangers, des laboratoires publics ou privés. 


\title{
Global financial crisis, liquidity pressure in stock markets and efficiency of central bank interventions
}

\author{
Mohamed El Hedi Arouri \\ LEO, University of Orleans and EDHEC, mohamed.arouri@univ-orleans.fr \\ Rue de Blois - BP 6739, 45067 Orléans cedex 2, France \\ Phone: +33238492410-Fax: +33238417380 \\ Fredj Jawadi* \\ Amiens School of Management and EconomiX-CNRS, fredj.jawadi@,supco-amiens.fr \\ 18, place Saint Michel, 80000 Amiens, France \\ Phone: +33 322822441 \\ * Corresponding author \\ Duc Khuong Nguyen \\ ISC Paris School of Management, France, dnguyen@groupeisc.com \\ 22, Boulevard du Fort de Vaux, 75017 Paris, France \\ Phone: +33140539999-Fax: +33140539898
}

\begin{abstract}
In this article, we investigate the hypothesis of efficiency of central bank intervention policies within the current global financial crisis. We firstly discuss the major existing interventions of central banks around the world to improve liquidity, restore investor confidence and avoid a global credit crunch. We then evaluate the short-term efficiency of these policies in the context of the UK, the US and the French financial markets using different modelling techniques. On the one hand, the impulse response functions in a Structural Vector Autoregressive (SVAR) model are used to apprehend stock market reactions to central bank policies. On the other hand, since these reactions are likely to be of an asymmetric and nonlinear nature, a two-regime Smooth Transition Regression-Generalized Autoregressive Conditional Heteroscedasticity (STR-GARCH) model is estimated to explore the complexity and nonlinear responses of stock markets to exogenous shifts in monetary policy shocks. As expected, our findings show strong repercussions from interest rate changes on stock markets, indicating that investors keep a close eye on central bank intervention policies to make their trading decisions. The stock markets lead monetary markets, however, when central banks are slow to adjust their benchmark interest rates.
\end{abstract}




\section{Introduction}

The question of whether shifts in monetary policy affect the stock markets has been widely examined in both academic and policy circles. In theory, there would be a significant response from stock markets in the short run since monetary policy exerts a significant impact on financial market conditions and stability by influencing asset prices and returns (Bernanke and Kuttner, 2005). All else being equal, the interventions by Central Banks (CBs) are said to be efficient in this case. Inversely, if the effect of monetary policy on stock market returns is insignificant, the changes that central banks would expect to see in the financial sector in order to achieve their macroeconomic objectives such as economic growth and inflation targets are unlikely to be made. Another intriguing issue is the complete opposite of the above question as it addresses the question of whether movements in stock prices provide guidelines for monetary policies (Rigobon and Sack, 2003). This tends to reflect the intuition that stock price fluctuations induced by market forces might contain relevant information to predict the the future conduct of monetary policy.

Hence, the investigation of the links between monetary policy and stock markets provides an effective means of understanding how monetary shocks are transmitted to the financial sector. Our paper attempts to empirically study the behavior of stock markets under the effects of monetary policy and to evaluate the resulting degree of short-run efficiency of CB actions. The latter can be defined by the accuracy and rapidity of stock market reactions with respect to a shift in monetary policy in the direction expected by CBs. Our study contributes to the related literature in several ways. Firstly, we add further evidence regarding the causality between monetary policy and stock markets using aggregate data from three developed markets with three independent monetary policies: the US, the UK and France. Secondly, our study period is extended to cover the period of the current global financial crisis of 2007-2009. This enables to check whether stock market movements are consistent with the actions undertaken 
by CBs whose joint effort has been to increase available funds by injecting liquidity into financial markets and to lower their key interest rates. The final contribution is methodological. Indeed, we firstly use the impulse response functions of a structural vector autoregressive model (SVAR) to apprehend stock market reactions to CB policies. Since these reactions are rather asymmetric and nonlinear, as noted by Chen (2007), we then estimate a two-regime STR-GARCH (Smooth Transition Regression combined with Generalized Autoregressive Conditional Heteroscedasticity) model to explore complexity and nonlinear responses of stock markets to exogenous shifts in monetary policy shocks. This model allows us to capture the potential of regime changes in both mean and variance processes as well as the leptokurtic distribution and volatility persistence of financial series.

Using changes in the three-month interest rates of the three respective countries as a measure of monetary policy innovations, we show significant responses by the US, the UK and French stock markets, which typically indicate that the investor community is keeping a close watch on $\mathrm{CB}$ intervention policies to make trading decisions. These findings are thus essentially in line with the previous literature. Furthermore, our empirical results indicate that the relationship between monetary shocks and the stock market is nonlinear and subject to regime shifts depending on the levels of interest rate changes.

The remainder of this article is organized as follows. Section 2 provides a short review of the literature with an emphasis on the current global financial crisis as a contextual framework for updating the theory of monetary policy and stock market relationships. Section 3 describes our econometric methodology and the data used. The main focus is on the specification, econometric implementation and estimation of the SVAR and STR-GARCH models. Section 4 reports and discusses the empirical results. Our concluding remarks and the policy implications are provided in Section 5. 


\section{A Short Review of the Literature}

The study of monetary and stock market interaction is of great interest to economists and policymakers and was the aim of an important literature of quantitative financial economics. We review major findings from relevant studies in the field and outline their extensions.

To begin, Thorbecke (1997), Patelis (1997), Conover et al. (1999), Ehrmann and Fratzscher (2004), Bernanke and Kuttner (2005), Durham (2005), He (2006), Chen (2007), and Bjørnland and Leitemo (2009), have investigated the above issue within the context of the US stock markets. They report a significant impact of Fed rate changes on stock markets. For example, Bernanke and Kuttner (2005) analyze the impact of unexpected shifts (or surprises) in monetary policy on equity prices. In their study, the unexpected target fund rate change is derived from the change in the rate suggested by the current-month future contracts after the FOMC's (Federal Open Market Committee) decisions, and the anticipated component of policy change is then calculated by the difference between the actual change in fund rate and the surprise. By running a linear regression model where the dependent variable is the daily return on the CRSP value-weighted portfolio and two independent variables refer to the surprise and expected components of the Federal funds rate respectively, the authors find that stock markets react strongly to surprise changes in the funds rate. Specifically, an unexpected reduction of 25 basis points in the Federal funds rate is associated with a rise of about $1 \%$ in the CRSP index. The reaction represents, however, a small, albeit significant, part of the changes in stock market returns. Chen (2007) focuses on the asymmetric effects of US monetary policies on equity returns during the periods of either bull or bear trends in stock markets. His results show that tightening monetary policy has a greater impact on monthly stock returns for the S\&P 500 index during bear trend periods, and that it increases the likelihood of switching to a bear market. 
Lobo (2002) also finds evidence of weak stock price reaction with respect to the Fed's news, but observes clear regime-switching in stock volatility from before to after rate change announcements. Empirical results from the asymmetric autoregressive exponential GARCH model are also consistent with the presence of asymmetries in the effects of the news. Bredin et al. (2007) investigate the influence of changes in the Bank of England's monetary policy on the behavior of the FTSE 100 index and some sectoral indices. Their results indicate that monetary policy shocks significantly influence aggregate stock market returns. With respect to sectoral stock returns, the reaction of discounting the official rate change is heterogeneous.

Applying cointegration methodology to investigate the interactions between countryspecific monetary policy and stock markets in the euro area, Cassola and Morana (2004) find that permanent monetary surprises have a strong impact on stock markets in the short-run. Bohl et al. (2007) address the issue of European stock market reaction to unexpected interest rate decisions by the ECB using identification through the heteroscedasticity approach proposed by Rigobon (2003). Their results indicate a negative and significant impact of the ECB's unexpected interest rate changes on the performance of four major national stock markets (France, Germany, Italy and Spain). The findings by Ioannidis and Kontonikas (2008) concerning the link between ECB monetary policy shifts and stock markets in France and the twelve other OECD countries over the period 1972-2002 are also consistent with those of previous studies. Miyao (2002) examines the effects of monetary policy on aggregate activity in Japan using a simple recursive VAR model and show that stock prices negatively respond to monetary policy actions over the period from January 1975 to April 1998.

There is also empirical evidence that monetary policy responds significantly to stock market movements. For instance, Rigobon and Sack (2003) attempted to quantify the magnitude of the US Fed's policy reaction to the stock market returns within a heteroscedasticity-based VAR model. Accordingly, they find that equity returns play a significant role in the Fed's 
monetary policy actions. Similarly, Bjørnland and Leitemo (2009) examine the reaction of monetary policy to equity prices in the context of the US using a structural VAR methodology, but their modeling approach further allows for both short- and long-run linkages between the monetary and stock market shocks. They typically find that a one percent increase in real stock prices leads to an interest rate increase of about 4 basis points.

In sum, empirical evidence from recent studies is consistent with significant stock market responses to shifts in monetary policies conducted by CBs. In this paper, we extend the scope of previous literature in that we examine the existence and the nature of the transmission of the Fed's and the Bank of England's target interest rates in the US, the UK and French stock markets during the present financial crisis. We proxy the monetary policy innovations by the changes in three-month interest rates of individual countries. Moreover, the fact that stock markets lag behind the CBs' financial help such as liquidity injections and interest rate cuts raises the question of the efficiency of $\mathrm{CB}$ actions. ${ }^{1}$ We test these hypotheses in linear and nonlinear framework.

\section{Empirical Methods and Data}

\subsection{Data and Preliminary Results}

This study aims to investigate the interaction between the stock markets and CB policies in the current international financial crisis. Therefore, we investigate data concerning three industrialized countries: the USA, the UK and France. The choice of the USA is justified by the fact that the financial crisis originated in the USA and this helps us to check the effects of the Federal Reserve decisions. Our choice also enables us to test how the financial crisis was transmitted to the other financial markets, how the Bank of England and the ECB reacted and

\footnotetext{
${ }^{1}$ Insofar as interest rate changes reflect shifts in monetary policy, we can note that between January $1^{\text {st }}, 2008$ and December 17, 2008, the Fed lowered its main interest rates seven consecutive times from $4.25 \%$ to $0.25 \%$. The Bank of England rate was reduced five times from $5.5 \%$ to $2 \%$. The ECB announced two increases and three decreases in its interest rates with an interest rate on December 10, 2008 being equal to $2 \%$.
} 
affected their stock markets through their actions on interest rates. Our sample data consists of closing stock prices (CAC40, Dow Jones and FTSE100 indices) and three-month interest rates. We employ daily frequency data over the period December 31, 2004 to March 19, 2009 in order to investigate this topic within the current international financial crisis. The data is obtained from Datastream and expressed in local currency. Note that the use of daily data is justified by the velocity and the speed with which both monetary and stock markets adjust.

First, we check the stationarity of our variables. For both the stock price and the interest rate series, the null hypothesis of unit root cannot be rejected, indicating that all series are integrated of order one for the three countries. ${ }^{2}$ We then compute the correlation matrix between interest rate changes and stock market returns in the same country as well as across the three countries we study. This provides an overview of the existing linkages between national stock markets and different CB policies.

From Table 1, we observe low correlations between stock returns and interest rate changes. As expected, these correlations are negative for the USA and the UK. Bilateral correlations between stock returns are over 50\%, suggesting significant contagion effects between stock markets. In particular, the correlation between French and British stock returns is about $93 \%$. Interestingly, bilateral correlations between interest rates are also positive and relatively high, which suggests possible coordination between American, European and British CBs. However, correlation tests are simply static linear measures and then these relationships should be checked using more robust tools.

\section{Insert table 1}

Then, the descriptive statistics presented in Table 2 suggest several interesting facts. First, all means in our series are negative, suggesting major undervaluation of these financial assets. Second, the high values of standard deviations imply some evidence of excessive volatility for

\footnotetext{
${ }^{2}$ Results of unit root tests are not presented but may be obtained upon request.
} 
both stock returns and interest rates. Third, symmetry and normality hypotheses are rejected for all series. This may be a sign of nonlinearity and asymmetry in the dynamic behavior of the series studied. We shall use linear and nonlinear econometric tools to examine the linkages between central bank policies and stock markets.

\section{Insert table 2}

\subsection{VAR modeling}

VAR models were introduced by Sims (1980) in order to capture the interdependencies between multiple time series and constitute a generalization of the univariate Autoregressive (AR) model. In a VAR model, we symmetrically address the importance and dynamic effects of various shocks such as the effects of monetary shocks on stock markets in our case.

Formally, we define a VAR model of order $\mathrm{p}$ by the following representation: ${ }^{3}$

$$
y_{t}=\mu_{t}+\sum_{i=1}^{p} A_{i} y_{t-i}+\varepsilon_{t}
$$

where: $y_{t}=\left(y_{1 t}, y_{2 t}, \ldots, y_{p t}\right)^{\prime}$ is a $(p \times 1)$ vector of endogenous variables, $\varepsilon_{t} \rightarrow N\left(0, \sum_{\varepsilon}\right)$ is a p-dimensional n.i.d error process with mean 0 and covariance matrix $\sum_{\varepsilon}$.

We estimate the VAR model for each country. ${ }^{4}$ In addition to the traditional variables, we introduce the current stock return and interest rate changes of the other countries in each VAR in order to capture the inter-correlation between stock markets and central banks as well as the contagion effects between central banks and stock markets. We report the main empirical results in tables 3, 4 and 5 .

\footnotetext{
${ }^{3}$ For more details regarding the econometric analysis of VAR models, see Hamilton (1994).

${ }^{4}$ The $\mathrm{p}$ order of a VAR model is determined using information criteria and autocorrelation functions.
} 
Let's start with France, where the stock return is significantly linked to UK and US returns, suggesting some evidence of contagion effects. The current French stock return is also correlated with French and US interest rates. This suggests significant comovements between monetary and stock markets, even though significant interest rate coefficients are not negative as in theory. The French interest rate is positively and significantly correlated with UK and US interest rates. It also depends on the lagged French stock return level, suggesting that monetary authorities adapt their monetary policy according to the performance of stock markets.

\section{Insert table 3}

For the UK, we show significant and positive linkages with French and US stock returns. The UK returns depend negatively on their previous levels, indicating also a correction for the UK market. Stock returns are also negatively correlated with US interest rates, implying that an interest rate decrease should positively and significantly affect the dynamism of the UK stock market. The UK interest rate also seems to be fixed in line with that of the ECB and the US Fed as well as according to stock market performance.

\section{Insert table 4}

For the US, the stock returns depend negatively and significantly on their previous values and they are significantly linked with the US interest rate, the French and UK returns, suggesting significant dependence on US monetary policies and some integration with European stock markets. The US interest rate is closely dependent on its previous level, reflecting Federal Reserve policies regarding the decrease in the interest rate. The latter is also negatively and significantly correlated with US stock returns, suggesting that a possible injection of liquidity may reassure investors and increase stock prices. The US interest rate is also positively and significantly linked with French and UK interest rates, reflecting the comovements of US and European monetary policies during the current international financial downturn.

\section{Insert table 5}


In order to improve and illustrate the linkages between monetary and stock markets, we have estimated the impulsion response function.

To do this, we orthogonalize the shock using Cholesky decomposition, define the shock as a standard deviation and study the effects of this shock over a 10-day period. ${ }^{5}$ For France, after a shock affecting the interest rate, the French return immediately decreases a little, then increases and persists for about seven days. This increase reflects the confidence of the French market, notably when the other markets have absorbed this shock. Concerning the interest rate, a positive shock occurring on the French market leads to an optimistic reaction through a lower but persistent interest rate increase.

\section{Insert graphic 1}

For the UK, an interest rate increase immediately implies an increase in stock returns but this will be absorbed after three days and become negative. Compared to the French case, we have the reverse scenario but with more symmetrical cycles for the UK. A stronger UK stock market may lead to an increase in the interest rate.

\section{Insert graphic 2}

US stock market (respectively US monetary market) reactions after a shock affecting the US monetary market (respectively US stock market) are very similar to those in the UK, but phase durations and sizes are more significant in the US.

During the current international financial crisis, stock markets are strongly under-valued. Financial assets have lost over $50 \%$ in just a few days and most stock markets are extremely volatile. To save the banks and financial markets, CBs have tried to stimulate liquidity by decreasing their interest rates hard in several stages. VAR estimations show significant linkages between stock markets and monetary policies. However, VAR modeling is based on

\footnotetext{
${ }^{5}$ See Hamilton (1994) for more details regarding the construction of impulse response functions.
} 
linear modeling which cannot reproduce asymmetrical linkages. The linear impulse response functions also capture only symmetrical reactions.

In order to adequately reproduce the interactions between stock and monetary markets, we extended our analysis to the nonlinear framework. In particular, we used a two-regime STRGARCH, which enables to capture the potential of regime changes in mean and variance processes in particular, as well as leptokurtic distribution, asymmetry and volatility persistence. This modeling also enables to explore complexity and nonlinear stock market responses to exogenous shifts in monetary policy shocks. It defines two types of regime: a "chartist" regime in which the current stock return is fully determined by its prior tendency, and the "monetary" regime that defines stock market returns according to interest rate changes. Otherwise, the use of GARCH model is documented by the ARCH effect detected in the stock returns when applying an $\mathrm{ARCH}$ test (table 6).

\section{Insert graphic 3}

\section{Insert table 6}

\subsection{STR-GARCH modeling}

Nonlinear models and the so-called regime-switching models are very popular in applied econometrics. This modeling enables different states for time series to be defined and characterized. In particular, STR-GARCH models specify different regimes for the time-series mean and variance and allow them to depend upon the regimes. We briefly discuss the STRGARCH modeling and we then discuss the main obtained findings. 


\subsubsection{STR-GARCH model}

STAR models and their statistical properties were developed by Teräsvirta (1994) as a generalization of TAR (Threshold Autoregressive) models. They constitute a combination of two linear representations that are linear per regime but nonlinear over the period. STAR models define two distinct regimes that are dependent on a transition function $\mathrm{F}($.) which is continuous and bounded between 0 and 1. STAR models include only lagged endogenous variables as explanatory variables, whereas the introduction of other exogenous variables in STAR models defines a multivariate model called STR models.

STR-GARCH models are an extension of STR models that allow their errors to have a conditional variance distributed as in GARCH models. These models are developed by Franses, Neeleand Van Dijk (1998), Lundbergh and Teräsvirta (1999, 2002). The transition between regimes is also smooth rather than abrupt. This smoothness is justified in several ways: the presence of transaction costs (Dumas, 1992; Anderson, 1997; Michael et al., 1997 among others), the coexistence of heterogeneous beliefs and investors, each of whom may switch sharply but perhaps at different times, which may induce different regimes and nonlinearity (Boswijk et al., 2007; Jawadi, 2009).

Formally, a STR-GARCH model corresponds to a mean equation defined by a smooth regression and to a variance equation given by a standard GARCH model such as:

$$
\begin{aligned}
y_{t}= & \left(\alpha_{0}+\alpha_{1} y_{t-1}+\cdots+\alpha_{p} y_{t-p}+\beta_{1} x_{t-1}+\cdots+\beta_{p} x_{t-p}\right) \times\left[1-F\left(s_{t}, \gamma, c\right)\right] \\
& \left(\alpha^{\prime}{ }_{0}+\alpha^{\prime}{ }_{1} y_{t-1}+\cdots+\alpha^{\prime}{ }_{p} y_{t-p}+\beta^{\prime}{ }_{1} x_{t-1}+\cdots+\beta^{\prime}{ }_{p} x_{t-p}\right) \times F\left(s_{t}, \gamma, c\right)+\varepsilon_{t}
\end{aligned}
$$


where: $y_{t}$ is the endogenous variable, $x_{t}$ is an explanatory variable, $\gamma$ is the transition speed $(\gamma$ $>0), \mathrm{p}$ is the $\mathrm{p}$-order of $\mathrm{AR},\left(\alpha_{0}, \alpha_{1}, \beta_{1}, \beta_{p}\right)$ and $\left(\alpha^{\prime}{ }_{0}, \alpha^{\prime},{ }_{1}, \beta^{\prime}{ }_{1}, \beta^{\prime}{ }_{p}\right)$ are respectively coefficients of the $1^{\text {st }}$ and $2^{\text {nd }}$ regime of the STR-GARCH model, $\mathrm{s}_{\mathrm{t}}$ is the transition variable, $\mathrm{c}$ is the threshold parameter, $F\left(s_{t}, \gamma, c\right)$ is the transition function, $\varepsilon_{t}=v_{t} \sqrt{h_{t}}$ and $v_{t}^{i i d} \rightarrow N(0,1)$

$$
F\left(s_{t}, \gamma, c\right)=\left[1+\exp \left\{-\gamma\left(\frac{s_{t}-c}{\sqrt{h_{t-d}}}\right)\right\}\right]^{-1}, \gamma>0
$$

$$
\begin{aligned}
& F\left(s_{t}, \gamma, c\right)=1-\exp \left\{-\gamma\left(\frac{s_{t}-c}{\sqrt{h_{t-d}}}\right)^{2}\right\}, \gamma>0 \\
& h_{t}=\phi_{0}+\phi_{1} \varepsilon_{t-1}^{2}+\ldots .+\phi_{q} \varepsilon_{t-q}^{2}+\theta_{1} h_{t-1}+\ldots .+\theta_{q} h_{t-q}^{2}
\end{aligned}
$$

From Teräsvirta (1994), the transition function is either logistic or exponential defining respectively the Logistic STR-GARCH (system $(2,3)$ : LSTR-GARCH) model and the Exponential STR-GARCH (system (2,4): ESTR-GARCH) model. The equation (5) describes the conditional volatility $h_{t}$ through a GARCH model where $\mathrm{q}$ is the q-order of the GARCH model. Both LSTR-GARCH and ESTR-GARCH models imply the existence of two distinct regimes with potentially different dynamic properties, while the transition between these regimes is smooth.

In practice, STR-GARCH models have recently been used by Arango et al. (2002), Qing-Min and he-Rui (2006) to study the linkages between stock and monetary markets. In a study concerning the Bogota stock market and the interest rate, Arango et al. (2002) show an inverse nonlinear relationship and suggest some evidence of nonlinear linkages between stock 
returns and interest rates. Qing-Min and he-Rui (2006) studied the correlation between stock and monetary markets for Hong Kong using STR-stochastic volatility models. The authors showed a nonlinear and negative relationship between stock indexes and interest rates. They also indicated that stock index is influenced more by itself than by the interest rate.

In this study, we consider that because of the current international financial downturn, these markets are more closely linked than in normal periods. We therefore suggest that the information is transmitted more rapidly from central banks to investors, implying a priori more rapid transition between regimes, leading us to prefer LSTR to ESTR representations to identify the linkage regimes between monetary and stock markets. Such hypotheses may be checked a posteriori through the misspecification tests.

\subsubsection{LSTR-GARCH estimation results}

The modeling steps of the STR-GARCH model are very similar to those of STAR models developed by Teräsvirta (1994). In the first step, we specify the p-order of the linear model using information criteria and autocorrelation functions. We then test the linearity against STR using Multiplier Lagrange tests (noted LM tests) ${ }^{6}$ and specify the transition function. We estimate the STR model for the conditional mean, test the null of no ARCH, and, if rejected, we estimate a STR-GARCH model in the second step. We finally apply misspecification tests in order to test the validity of estimation results.

Thus, we model the stock returns via STR-GARCH model while introducing the lagged interest rate as an explanatory variable in the STR-GARCH model. The lagged interest rate is also retained as a transition variable $\left(\mathrm{s}_{\mathrm{t}}\right)$ in order to capture the dependence of stock markets toward monetary markets. This can also help to test whether a shift in interest rates implies a shift in investors' opinions and then in stock markets or not. For the USA, we test the linkag-

\footnotetext{
${ }^{6}$ See Van Dijk et al. (2002) for more details about the linearity tests.
} 
es between the US interest rate and the US stock market and the direct impact of the financial crisis on the stock market. However, for the UK and France, this effect is tested implicitly. Indeed, while investigating the linkages between stock returns and interest rates in a nonlinear framework, we implicitly test the dependency of the European stock markets on the US market. Indeed, we suppose that through the transmission mechanisms between US, French and UK interest rates, the crisis effect continues to be transmitted. For this reason, we propose leaving out the US variables (stock return and interest rate) when estimating the LSTRGARCH models for France and the UK.

In practice, we find first that the optimal value is $p=1$ for France and $p=2$ for the UK and the USA. We then estimate an AR(1) for France and an AR(2) for the UK and the USA in which the lagged local interest rate is retained as an explanatory variable. Second, we test the linearity hypothesis against its alternative of nonlinearity of STR type for several values of d $(1 \leq d \leq 5)$. The null hypothesis is significantly rejected, suggesting that the adjustment of the monetary and stock markets is rather nonlinear. Interestingly, the linearity is more rejected when the transition variable $s_{t}$ corresponds to the first lagged deviation of interest rates $(d=1)$. This finding clearly suggests a nonlinear mean-reversion between stock and monetary markets. The rejection of linearity also reflects the instability, asymmetry and persistence induced by the current international financial crisis. In addition, the choice of the first lagged interest rate change as a transition variable highlights the short-term dependency between monetary policies and stock markets. Indeed, after each interest rate innovation, most investors try to benefit rapidly from the interest shift and the later is rapidly transmitted to the stock markets.

We thus estimate $\operatorname{LSTR}(2,1)-\operatorname{GARCH}(1,2), \operatorname{LSTR}(1,1)-\operatorname{GARCH}(1,1)$ and $\operatorname{LSTR}(2,1)-$ $\operatorname{GARCH}(1,1)$ model for American, French and British stock returns respectively. ${ }^{7}$ These models were estimated by the quasi-maximum likelihood. According to Press et al. (1988),

\footnotetext{
${ }^{7}$ The $\mathrm{p}$ and $\mathrm{q}$ orders of GARCH models are also specified through information criteria and a general-to- specific estimation procedure of GARCH models.
} 
robust estimates of the covariance matrices of the parameter estimates are calculated by the numerical algorithm of Broyden, Fletcher, Goldfarb, and Shanno (BFGS), because the normality hypothesis is not checked and this should imply consistent estimators. The estimation results of LSTR models are reported in table 8, while we recall in what follows the empirical LSTR-GARCH model that we estimate for the USA for example.

$$
\begin{aligned}
& y_{t}=\alpha_{0}+\alpha_{1} y_{t-1}+\alpha_{2} y_{t-2}+\beta_{1} x_{t-1} \times\left[1+\exp \left\{-\gamma\left(\frac{x_{t-d}-c}{\sqrt{h_{t-d}}}\right)\right\}\right]^{-1}+\varepsilon_{t} \\
& h_{t}=\phi_{0}+\phi_{1} \varepsilon_{t-1}^{2}+\theta_{1} h_{t-1}+\theta_{2} h_{t-2}
\end{aligned}
$$

where: $\mathrm{y}_{\mathrm{t}}$ is the US stock return and $\mathrm{x}_{\mathrm{t}}$ is US interest rate deviations.

Overall, our findings show significant and negative dependence of the current stock return to its previous levels for the three indexes considered. This rejects the weak efficiency form, implies structure dependence in stock returns and indicates that all the stock markets studied are currently under correction. For the interest rate effects, they are economically significant, but negative only for the UK and the USA, indicating that a decrease in interest rates leads to an appreciation of the stock markets.

\section{Insert table 7}

Furthermore, the GARCH model estimators are of the correct sign and are statistically significant. The estimation of the logistic function shows significant estimators for the transition speed and the threshold parameter. This provides strong evidence of nonlinear relationship between stock returns and interest rates. It indicates that after a $\mathrm{CB}$ action on interest rates, the stock return deviates and shifts from one regime to another, notably when the interest rate 
deviation exceeds a certain threshold. Particularly, the LSTR-GARCH model implies two distinct regimes for which the transition is relatively elevated.

Finally, the misspecification tests applied to the residuals of the estimated LSTR-GARCH models suggested by the Ljung-Box Q-statistics $\mathrm{AR}(\mathrm{p})$ and $\mathrm{ARCH}(\mathrm{p})$ indicate the ability of the nonlinear model to capture the serial dependence in the mean and the variance of stock returns for the three indexes. The no-remaining nonlinearity test indicates that the estimated LSTR-GARCH has also captured the nonlinearity inherent to the relationship between stock returns and interest rates.

\section{Concluding Remarks}

This article investigated the behavior of stock markets to the effects of monetary policy, and empirically assessed the degree of short-term efficiency of central bank actions on interest rates. We defined the latter by the accuracy and rapidity with which stock markets react with respect to a shift in monetary policy in the direction expected by central banks. We contributed to the related literature in several ways. First, we provided further empirical evidence on the relationship between monetary policy and stock markets using data from three developed markets: the US, the UK and France. Second, our study period has been extended to cover the period of the current global financial crisis of 2007-2009. Finally, different linear and nonlinear econometric techniques including SVAR and STR-GARCH are used to support our research objectives. STR-GARCH models are suitable for investigating the link between stock markets and interest rates especially during periods of turbulence and financial crisis. They allow the potential of regime changes in mean and variance processes to be captured as well as the persistent volatility of financial series.

Taken together, our findings showed significant responses to changes in interest rates by the US, the UK and French stock markets, which indicates that stock market investors keep a 
close watch on central bank intervention policies to make trading decisions. There are also significant cross-country effects. Interestingly, the link between stock market returns and interest rate innovations is not entirely linear as it changes from one regime to another depending on interest rate levels.

\section{References}

Anderson, H. M. (1997), “ Transaction Costs and Nonlinear Adjustment Towards Equilibrium in The US Treasury Bill Markets", Oxford Bulletin of Economics and Statistics, Vol.59, pp.465-484.

Bernanke, B., Kuttner, K. N. (2005) What explains the stock market's reaction to Federal Reserve policy, Journal of Finance, 60, 1221--1257.

Bjørnland, H. C., Leitemo, K. (2009) Indentifying the interdependence between US monetary policy and the stock market, Journal of Monetary Economics, 56, 275--282.

Bohl, M. T., Siklos, P. L., Sondermann, D. (2007) Shocking markets: European stock markets and the ECB's monetary surprises, Working Paper, University Münster, Germany.

Bollerslev, T. (1986) Generalized autoregressive conditional heteroscedasticity, Journal of Econometrics, 31, 307--327.

Boswijk, H. P. Hommes, C. H. and Manzan, S. (2007), "Behavioral Heterogeneity in Stock Prices”, Journal of Economic Dynamics and Control, Vol.31, Issue 6, June, pp.1938-1970.

Bredin, D., Hyde, S., Nitzsche, D., O'Reilly, G. (2007) UK stock returns and the impact of domestic monetary policy shocks, Journal of Business Finance and Accounting, 34, 872--888. Cassola, N., Morana, C. (2004) Monetary policy and the stock market in the euro area, Journal of Policy Modeling, 26, 387--399.

Chen, S-S. (2007) Does monetary policy have asymmetric effects on stock returns, Journal of Money, Credit and Banking, 39, 667--688. 
Conover, C. M., Jensen, G. R., Johnson, R. R. (1999) Monetary environments and international stock returns, Journal of Banking and Finance, 23, 1357--1381.

Durham, J. B. (2005) More on monetary policy and stock price returns, Financial Analyst Journal, 61, 83--90.

Dumas, B. (1992), “ Dynamic Equilibrium and the Real Exchange Rate in a Spatially Separated World ”, Review of Financial Studies, №5, n², pp.153-180.

Ehrmann, M., Fratzscher, M. (2004) Taking stock: Monetary policy transmission to equity markets, Journal of Money Credit and Banking, 36, 719--738.

Escribano, A. and Jordã, O. (1999), "Improving Testing and Specification of Smooth Transition Regression Models", In Rothman P. (ed), Nonlinear Times Series Analysis of Economic and Financial Data, Boston: kluwer, pp. 298-319.

He, T. L. (2006) Variations in effects of monetary policy on stock market returns in the past four decades, Review of Financial Economics, 15, 331--349.

Ioannidis, C., Kontonikas, A. (2008) The impact of monetary policy on stock prices, Journal of Policy Modeling, 30, 33--53.

Jawadi, F.(2009) Essay in Dividend Modelling and Forecasting: Does Nonlinearity Help?, Applied Financial Economics, 19, 16, 1329-1343.

Lobo, B. J. (2000) Asymmetric effects of interest rate changes on stock prices, Financial Review, 35, 125--143.

Michael, P. Nobay A. R. and Peel, D. A. (1997), "Transaction costs and Nonlinear Adjustment in Real Exchange Rates: An Empirical Investigation", Journal of Political Economy, n $105, \mathrm{pp} .862-879$.

Miyao, R. (2002) The effects of monetary policy in Japan, Journal of Money, Credit and Banking, 34, 376--392. 
Patelis, A. D. (1997) Stock return predictability and the role of monetary policy, Journal of Finance, 52, 1951--1972.

Press W., Flannery S., Teukolsky S.W (1988). Vettering, Numerical Recipes in C, Cambridge University Press, New York.

Rigobon, R. (2003) Identification through heteroscedasticity, Review of Economics and Statistics, 85, 777--792.

Rigobon, R., Sack, B. (2003) Measuring the reaction of monetary policy to the stock market", Quarterly Journal of Economics, 118, 639--669.

Sims, C. A. (1980) Macroeconomics and Reality, Econometrica, 48, 1--47.

Teräsvirta, T. (1994), "Specification, Estimation and Evaluation of Smooth Transition Autoregressive Models", Journal of the American Statistical Association, Vol.89, $\mathrm{n}^{\circ} 425$, pp.208-218.

Thorbecke, W. (1997) On stock market returns and monetary policy, Journal of Finance, 52, 635-654.

Van Dijk, D., Teräsvirta, T., Franses, F. (2002) Smooth transition autoregressive models - A survey of recent developments, Econometric Reviews, 21, 1--47. 


\section{Appendices}

Table 1: Correlation matrix

\begin{tabular}{cccccrr}
\hline \hline & DIF & RF & DIU & RU & DIUK & RUK \\
\hline DIF & 1.00 & 0.00 & 0.38 & -0.05 & 0.47 & -0.03 \\
RF & & 1.00 & 0.01 & 0.54 & -0.01 & 0.93 \\
DIU & & & 1.00 & -0.02 & 0.30 & -0.02 \\
RU & & & & 1.00 & -0.05 & 0.52 \\
DIUK & & & & 1.00 & -0.03 \\
RUK & & & & & 1.00 \\
\hline \hline
\end{tabular}

Note: $(D I F, R F),(D I U, R U)$ and $(D I U K, R U K)$ denote respectively interest rate changes and stock returns for respectively France, the USA and the UK.

Table 2: Descriptive Statistics

\begin{tabular}{lcccccc}
\hline \hline & DIF & RF & DIU & RU & DIUK & RUK \\
\hline Mean & $-4.93 \mathrm{E}-06$ & -0.003 & $-1.15 \mathrm{E}-05$ & -0.0003 & $-2.80 \mathrm{E}-05$ & -0.0002 \\
Maximum & 0.001 & 0.11 & 0.003 & 0.11 & 0.002 & 0.09 \\
Minimum & -0.001 & -0.09 & -0.004 & -0.08 & -0.011 & -0.09 \\
Std. Dev. & 0.0002 & 0.02 & 0.0004 & 0.01 & 0.0004 & 0.02 \\
Skewness & -1.11 & 0.12 & -2.66 & 0.01 & -16.13 & -0.13 \\
Kurtosis & 12.72 & 13.00 & 38.21 & 14.51 & 410.42 & 12.78 \\
Jarque-Bera & 4542.35 & 4573.56 & 57982.8 & 6062.15 & 7634819.0 & 4372.57 \\
Probability & 0.00 & 0.00 & 0.00 & 0.00 & 0.00 & 0.00 \\
\hline \hline
\end{tabular}

Note: $(D I F, R F),(D I U, R U)$ and $(D I U K, R U K)$ denote respectively interest rate changes and stock returns for respectively France, the USA and the UK.

Table 3: VAR estimation for France

\begin{tabular}{ccc}
\hline \hline & RF & DIF \\
\hline RF(-1) & 0.0002 & 0.0007 \\
RF(-2) & {$[0.02]$} & {$[3.31]$} \\
DIF(-1) & 0.02 & 0.0002 \\
& {$[1.69]$} & {$[0.81]$} \\
DIF(-2) & -0.80 & 0.48 \\
C & {$[-0.58]$} & {$[16.61]$} \\
DIU & 2.35 & 0.17 \\
& {$[1.80]$} & {$[6.25]$} \\
DIUK & $-3.38 \mathrm{E}-05$ & $1.42 \mathrm{E}-06$ \\
RU & {$[-0.21]$} & {$[0.42]$} \\
& 0.92 & 0.05 \\
RUK & {$[2.10]$} & {$[5.09]$} \\
& 0.59 & 0.09 \\
& {$[1.39]$} & {$[10.2496]$} \\
Adj. R-squared & 0.08 & -0.0008 \\
F-statistic & {$[5.80]$} & {$[-2.99]$} \\
Log likelihood & 0.98 & 0.0003 \\
\hline \hline are & {$[73.84]$} & {$[1.18]$} \\
\hline DStudents. & 0.88 & 0.60 \\
& 1024.65 & 207.23 \\
& 4197.79 & 8420.55 \\
\hline
\end{tabular}

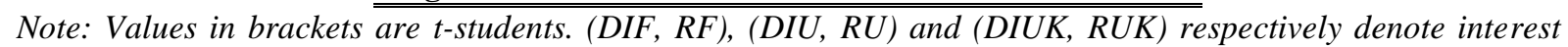
rate changes and stock returns for respectively France, the USA and the UK. 
Table 4: VAR estimation for the UK

\begin{tabular}{ccc}
\hline \hline & RUK & DIUK \\
\hline \hline RUK(-1) & -0.02 & 0.001 \\
RUK(-2) & {$[-1.37]$} & {$[1.81]$} \\
DIUK1(-1) & -0.02 & 0.001 \\
DIUK1(-2) & {$[-2.32]$} & {$[0.82]$} \\
C & 0.39 & 0.14 \\
& {$[0.97]$} & {$[4.81]$} \\
DIF1 & -0.58 & 0.003 \\
& {$[-1.48]$} & {$[0.11]$} \\
DIU1 & $2.58 \mathrm{E}-05$ & $-1.78 \mathrm{E}-05$ \\
& {$[0.17]$} & {$[-1.66]$} \\
RF & -1.12 & 0.85 \\
& {$[-1.11]$} & {$[11.67]$} \\
RU & -1.06 & 0.15 \\
& {$[-2.53]$} & {$[4.89]$} \\
& 0.85 & 0.0005 \\
Log likelihood & {$[73.72]$} & {$[0.63]$} \\
\hline \hline
\end{tabular}

Note: Values in brackets are t-students. (DIF, RF), (DIU, RU) and (DIUK, RUK) respectively denote interest rate changes and stock returns for respectively France, the USA and the UK.

Table 5: VAR estimation for the USA

\begin{tabular}{ccc}
\hline \hline & RU & DIU1 \\
\hline RU(-1) & -0.36 & -0.002 \\
RU(-2) & {$[-14.32]$} & {$[-3.37]$} \\
DIU1(-1) & -0.06 & -0.004 \\
DIU1(-2) & {$[-2.54]$} & {$[-5.96]$} \\
& 2.67 & 0.45 \\
C & {$[2.64]$} & {$[15.50]$} \\
DIF1 & -0.79 & 0.01 \\
& {$[-0.79]$} & {$[0.39]$} \\
DIUK1 & -0.0003 & $-3.46 \mathrm{E}-06$ \\
& {$[-0.95]$} & {$[-0.37]$} \\
RF & -3.19 & 0.483394 \\
RUK & {$[-1.48]$} & {$[7.81]$} \\
& -0.02 & 0.09 \\
& {$[-0.02]$} & {$[3.37]$} \\
Adj. R-squared & 0.42 & 0.004 \\
F-statistic & {$[6.94]$} & {$[2.08]$} \\
Log likelihood & 0.20 & -0.003 \\
\hline \hline are & {$[3.03]$} & {$[-1.89]$} \\
\hline Studers. & 0.41 & 0.39 \\
& 97.12 & 89.17 \\
& 3426.45 & 7307.99 \\
\hline
\end{tabular}

Note: Values in brackets are t-students. (DIF, RF), (DIU, RU) and (DIUK, RUK) respectively denote interest rate changes and stock returns for respectively France, the USA and the UK. 


\section{Graphic 1: Impulse Response for France}

Response to Cholesky One S.D. Innovations \pm 2 S.E.

Response of RF to RF

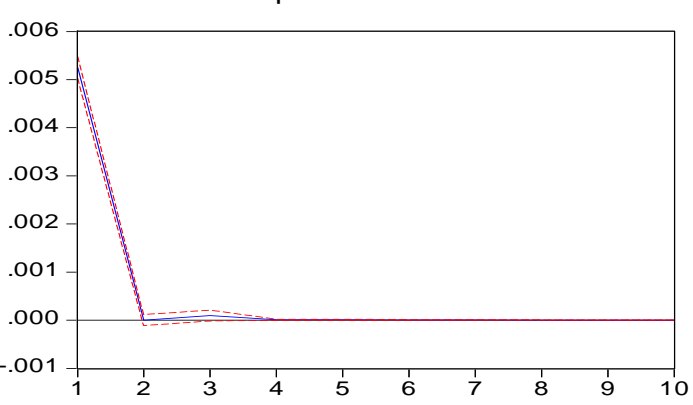

Response of DIF1 to RF

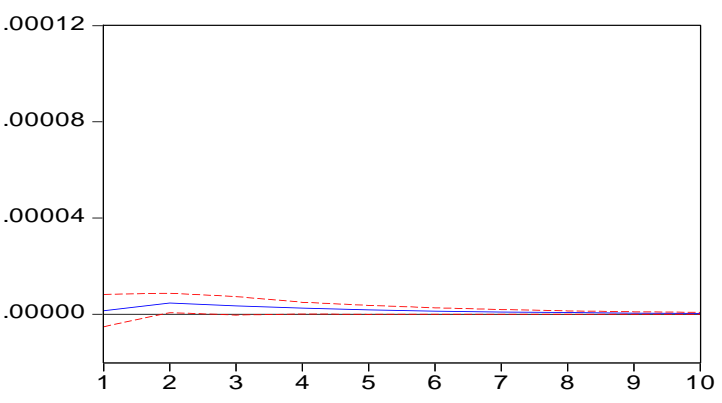

Response of RF to DIF 1

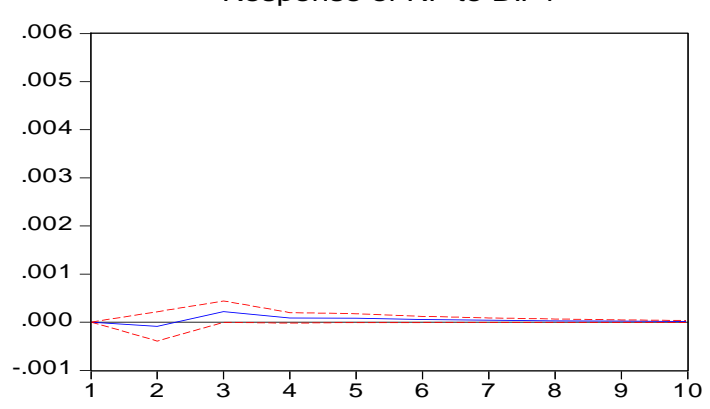

Response of DIF 1 to DIF 1

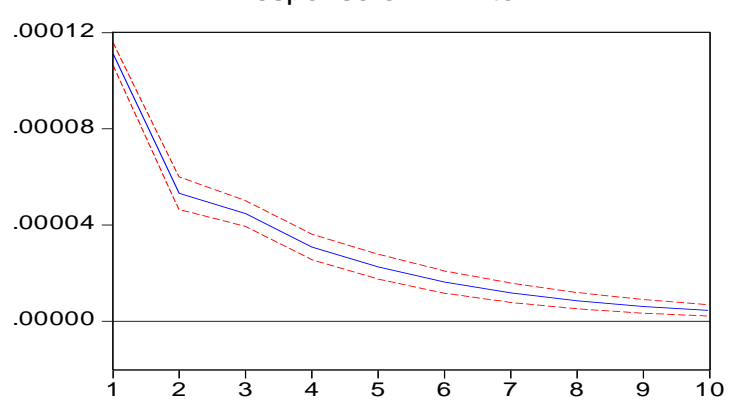

Graphic 2: Impulse Response for the UK

Response to Cholesky One S.D. Innovations \pm 2 S.E.

Response of RUK to RUK

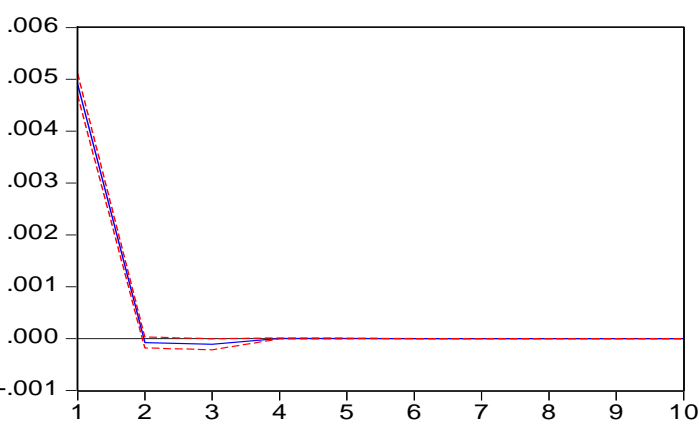

Response of DIUK1 to RUK

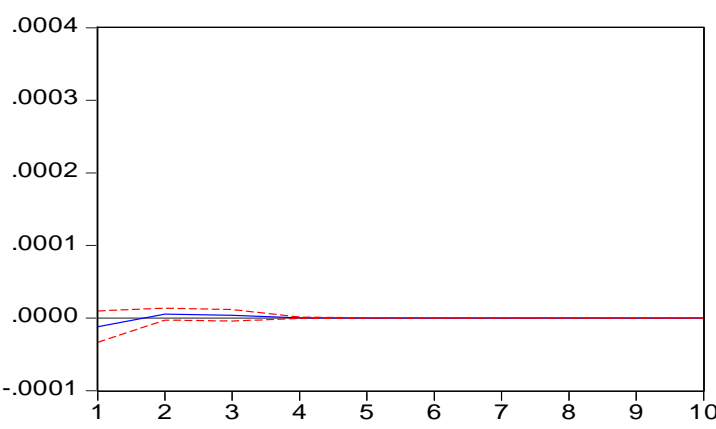

Response of RUK to DIUK1

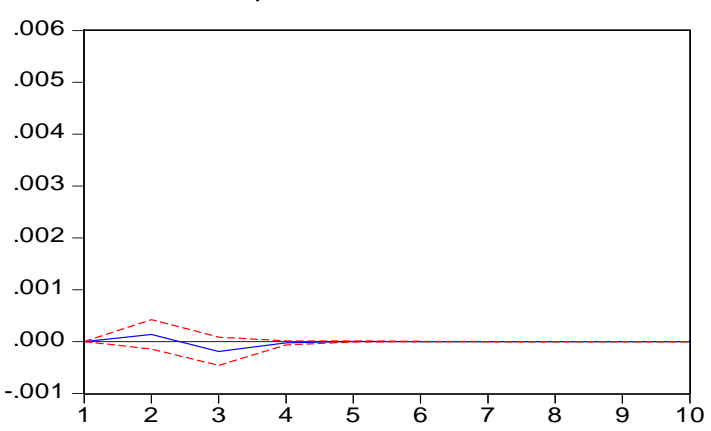

Response of DIUK1 to DIUK1

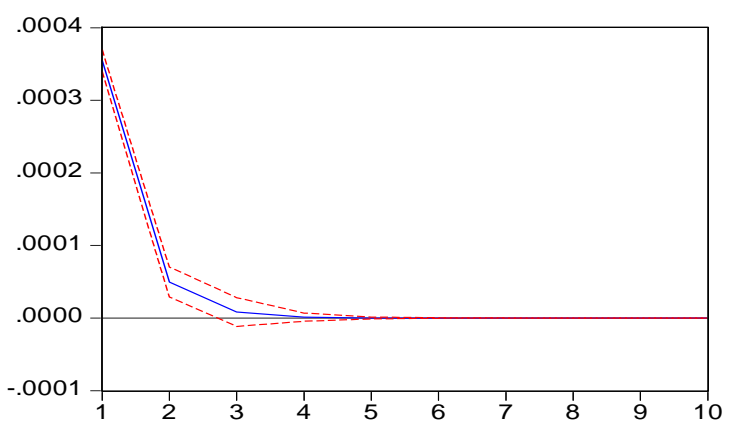


Graphic 3: Impulse Response for the USA

Response to Cholesky One S.D. Innovations \pm 2 S.E.

Response of $\mathrm{RU}$ to $\mathrm{RU}$

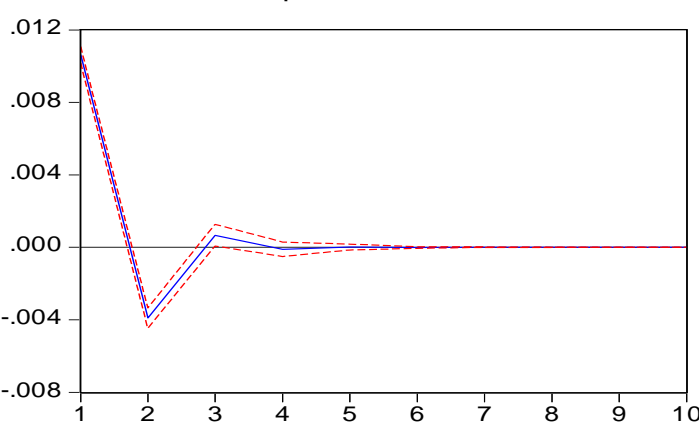

Response of DIU1 to RU

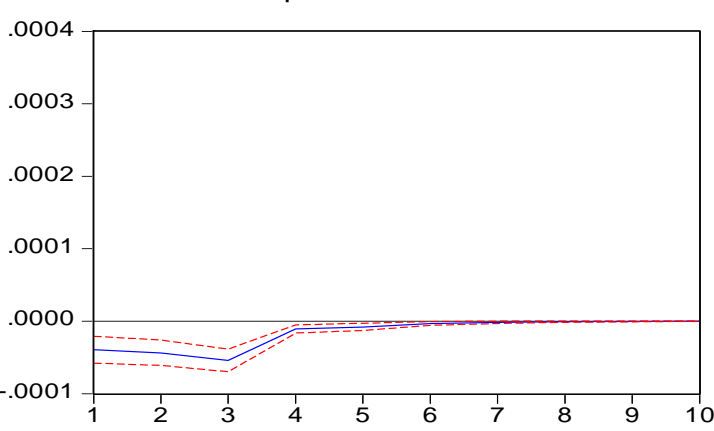

Response of RU to DIU1

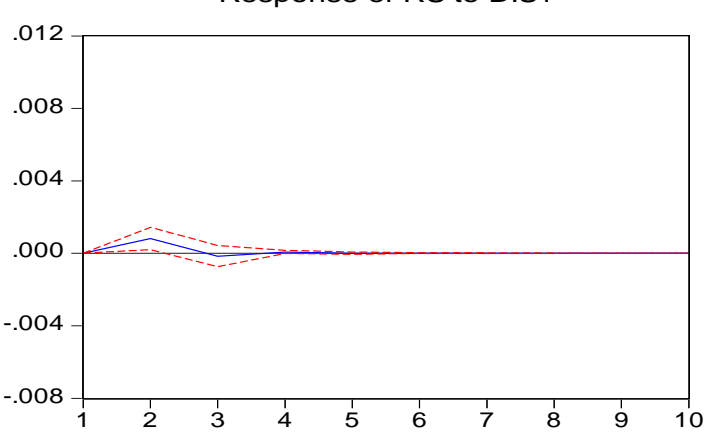

Response of DIU1 to DIU1

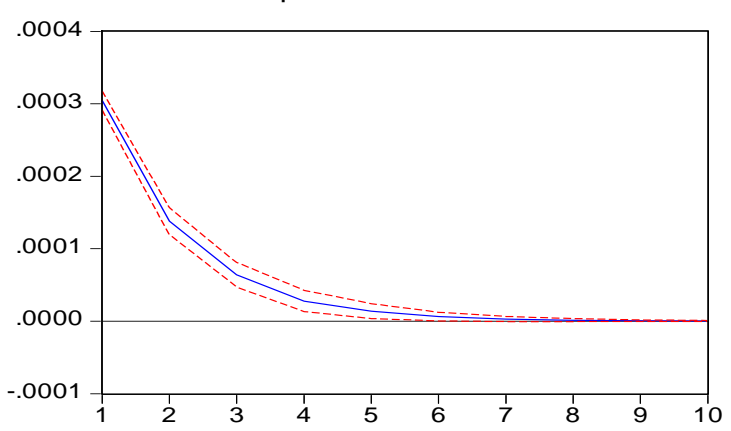

Table 6: ARCH tests

\begin{tabular}{cccc}
\hline \hline & \multicolumn{3}{c}{ ARCH statistics (q) } \\
\hline ARCH(2) & France & UK & USA \\
p-value & 123.78 & 117.27 & 209.73 \\
\hline \hline
\end{tabular}

Note: $\mathrm{q}$ is the q-order of the ARCH model. 
Table 7: LSTR-GARCH Estimation Results

\begin{tabular}{|c|c|c|c|}
\hline & France & $\overline{\mathbf{U K}}$ & USA \\
\hline \multicolumn{4}{|c|}{ Linear Part } \\
\hline \multirow{3}{*}{$\alpha_{0}$} & 0.0008 & 0.0007 & 0.0005 \\
\hline & {$[2.78]$} & [ 1.69$]$ & [ 2.43] \\
\hline & -0.078 & -0.081 & -0.085 \\
\hline \multirow[t]{2}{*}{$\alpha_{1}$} & {$[-2.71]$} & {$[-2.63]$} & [ -2.89] \\
\hline & & -0.08 & -0.05 \\
\hline \multirow[t]{2}{*}{$\alpha_{2}$} & & {$[-2.54]$} & {$[-2.69]$} \\
\hline & \multicolumn{3}{|c|}{ Nonlinear parts } \\
\hline \multirow{3}{*}{$\beta_{1}$} & 3.08 & -4.44 & -1.74 \\
\hline & [ 17.2] & {$[-6.50]$} & [ -1.99] \\
\hline & 71.4 & 47.6 & 26.02 \\
\hline \multirow[t]{2}{*}{$\gamma$} & [ 3.37] & {$[4.7]$} & [ 3.93$]$ \\
\hline & 0.003 & -0.013 & 0.04 \\
\hline \multirow[t]{2}{*}{$c$} & [4.33] & {$[-20.2]$} & {$[3.78]$} \\
\hline & $5 * 10^{-6}$ & $1 * 10^{-6}$ & $3 * 10^{-6}$ \\
\hline \multirow[t]{2}{*}{$\phi_{0}$} & [ 4.33] & [ 2.83] & [ 2.38$]$ \\
\hline & 0.203 & 0.24 & 0.15 \\
\hline \multirow[t]{2}{*}{$\phi_{1}$} & {$[5.7]$} & [ 6.67] & {$[7.5]$} \\
\hline & 0.78 & 0.77 & 0.84 \\
\hline \multirow[t]{2}{*}{$\theta_{1}$} & [ 25.08] & [ 25.3] & [ 37.4] \\
\hline & & & 0.91 \\
\hline$\theta_{2}$ & - & - & [ 63.03] \\
\hline \multicolumn{4}{|c|}{ Misspecification Tests } \\
\hline$A R(12)$ & 0.74 & 0.41 & 0.26 \\
\hline $\operatorname{ARCH}(12)$ & 0.30 & 0.29 & 0.27 \\
\hline NRNL & 0.79 & 0.25 & 0.68 \\
\hline$N$ & 19 & 19 & 21 \\
\hline
\end{tabular}

Note: AR(12), ARCH (12) and NRNL designate the p-value of Ljung-Box Test for $12^{\text {th }}$ order autocorrelation, the p-value of ARCH test for $12^{\text {th }}$ order and the p-value for no-remaining nonlinearity. Values between [.] are based on robust estimates of the covariance matrices of the parameter estimates. 